\title{
COMPOSIÇÃO MINERAL DA FOLHA EM ABACAXIZEIRO: EFEITO DA PARTE DA FOLHA ANALISADA ${ }^{1}$
}

\author{
SUSANA CRISTINE SIEBENEICHLER ${ }^{2}$, PEDRO HENRIQUE MONNERAT ${ }^{3}$, \\ ALMY JUNIOR CORDEIRO DE CARVALHO ${ }^{4}$, JOSÉ ACCÁCIO DA SILVA ${ }^{5}$
}

\begin{abstract}
RESUMO - A padronização da amostragem para a análise foliar em abacaxizeiros é importante para a obtenção de resultados confiáveis. Neste aspecto, este trabalho visa a esclarecer a variação da composição mineral da folha de abacaxi, em plantas desenvolvidas em solo arenoso, sem irrigação. As folhas foram coletadas, limpas e divididas em 4 porções: aclorofilada, basal, mediana e apical. Após a secagem, as amostras foram pesadas, submetidas à digestão e analisadas pela metodologia adequada a cada nutriente. Uma grande variação no teor dos nutrientes foi encontrada ao longo da folha de abacaxi. Uma comparação confiável pode ser estabelecida entre as análises feitas com a folha inteira e a porção clorofilada da folha; o mesmo já não pode ser dito para a porção aclorofilada. Assim, este trabalho vem confirmar a necessidade da padronização da amostragem.
\end{abstract}

Termos para indexação: Annanas comosus, fruticultura, abacaxi, nutrientes foliares

\section{MINERAL COMPOSITION OF THE LEAF IN PINEAPPLE: EFFECT OF THE PART OF THE ANALYSED LEAF}

\begin{abstract}
The standardization of the sampling for foliar analysis in pineapple is important to obtain reliable results. In this aspect this work seeks to identify the variation of the mineral composition of pineapple leaf, in plants developed in sandy soil, without irrigation. The leaves were collected, cleaned and divided in 4 parts: non-chlorophyllated, basal, medium and apical. After the drying, the samples were weighted, digested, and analyzed by the appropriate methodology for each nutrient. A great variation in the concentration of the nutrients was found along the pineapple leaf. A reliable comparison of the analysis can be established between the whole leaf and the chlorophyllated portion of the leaf; the same does not apply to the non-chlorophyllated portion of the same leaf. This paper confirms the need of the standardization of leaf sampling for mineral composition evaluation.
\end{abstract}

Index terms: Annanas comosus, leaf nutrient status, horticulture, pineapple

\section{INTRODUÇÃO}

A análise foliar é um método muito utilizado na avaliação do estado mutricional de plantas. O uso da folha justifica-se por esta ser o órgão que melhor reflete o estado nutricional da planta (Malavolta et al., 1997).

A distribuição dos nutrientes minerais na planta e em cada uma de suas partes não é homogênea, e, mesmo ao longo da folha, podem-se observar teores diferenciados, mostrando a necessidade da padronização das amostras (Jones et al., 1991).

A diagnose do estado nutricional pela análise foliar apresenta certos inconvenientes, sendo necessário o máximo de cuidado na coleta das amostras para se ter a melhor padronização possível e, conseqüentemente, melhor exatidão, principalmente para plantas de abacaxi, onde a variação dos nutrientes é muito grande entre as diversas folhas da planta. Para diminuir este problema, foi feita a classificação das folhas do abacaxizeiro, da base para o ápice, em 6 categorias: $\mathrm{A}$ e $\mathrm{B}=$ senis; $\mathrm{C}=$ maduras; $\mathrm{D}$ $=$ ativas; $\mathrm{E} \mathrm{e} \mathrm{F}=\mathrm{em}$ via de crescimento (Malavolta, 1982).

Até o momento, os pesquisadores não chegaram a um consenso quanto à parte da folha a ser utilizada na diagnose, ou se utilizam a folha inteira. As pesquisas realizadas no Hawai utilizam o terço médio da porção não clorofilada da folha, e as desenvolvidas na França tendem a utilizar a folha inteira (Souza, 1999).

O Quadro 1 apresenta os teores dos nutrientes considerados adequados para o abacaxizeiro em diferentes referências bibliográficas. Neste, pode-se observar que existe uma variação entre os teores dos nutrientes, principalmente para os macronutrientes, em diferentes partes da folha, por exemplo, ao se comparar a porção clorofilada com a aclorofilada.

Estes dados demonstram o quanto é problemática a falta de padronização das amostragens, pois está evidente que não se pode utilizar uma ou outra parte da folha na análise foliar, como sugerem alguns autores.

Em parte, esta variação pode ser atribuída à época de amostragem, mas parece que também não se dá muita atenção a este fator. Malavolta (1992) e Malavolta et al.(1997) citam que a amostragem deve ser feita no verão, mas não se referem à idade da planta. A amostragem antes da indução floral foi citada por Boaretto et al.(1999). Os autores Reuter e Robinson (1988) sugerem fazer as amostragens aos 7, 9, 11 e 16 meses após o

1 (Trabalho 205/2000). Recebido: 11/09/2000. Aceito para publicação: 21/08/2001.

2 Eng. Agr. Doutoranda em Fitotecnia - Produção Vegetal, UENF, Campos dos Goytacazes, RJ. e-mail: sieben@uenf.br

3 Eng. Agr. PhD em Nutrição Mineral de Plantas. Professor Titular da UENF, Campos dos Goytacazes, RJ

4 Eng. Agr. Doutor em Produção Vegetal. Professor Adjunto da UENF, Campos dos Goytacazes, RJ

5 Eng. Quím. Técnico de Nível Superior da UENF, Campos dos Goytacazes, RJ 
plantio, mas não citam de qual época são os dados apresentados ou se estes são uma média destas amostragens, tornando-se inviável o seu uso na comparação de dados. Jones et al. (1991) sugerem a amostragem no início do florescimento.

Neste trabalho, objetivou-se esclarecer a variação da composição mineral da folha de abacaxi, demonstrando a importância da padronização da amostragem, pois, de acordo com a parte da folha utilizada na amostragem, a diagnose foliar poderá variar.

\section{MATERIAL E MÉTODOS}

O experimento foi conduzido em propriedade particular, no Distrito de Praça João Pessoa, Município de São Francisco de Itabapoana - RJ, utilizando uma área cultivada com abacaxi, var. Pérola.

O plantio foi realizado em abril de 1999, e o florescimento foi induzido em maio de 2000. A amostragem foi realizada aos 7; 9; 11; 13 e 15 meses após o plantio. Neste trabalho, utilizaram-se somente os dados referentes à primeira coleta de folhas, feita em novembro de 1999.

O experimento foi constituído de parcelas-testemunha e das que receberam adubação bórica foliar mensal. A aplicação foliar foi feita com uma solução de bórax a $0,3 \%$.

Cada parcela era constituída de duas fileiras duplas $(0,50$ x 0,30 m) espaçadas de $1,00 \mathrm{~m}$, com 4,20 m de comprimento, contendo 56 plantas; sendo consideradas úteis as 20 plantas centrais. $\mathrm{O}$ delineamento utilizado foi o de blocos casualizados completos, com 4 repetições.

A amostra consistiu de 5 folhas " $\mathrm{D}$ ", coletadas em plantas diferentes dentro da área útil de cada parcela. A coleta foi realizada na parte da manhã, entre 9 e $12 \mathrm{~h}$. No laboratório, as folhas foram limpas com algodão umedecido com água desionizada e secionadas em 4 partes: aclorofilada, basal, mediana e apical. A seguir, as partes das folhas foram secas em estufa de circulação forçada de ar, a $70-75^{\circ} \mathrm{C}$, por 72 horas. Após secas, as amostras foram pesadas e moídas em moinho tipo Willey, passadas em peneira de 20 mesh e armazenadas em frascos hermeticamente vedados.

$\mathrm{O} \mathrm{N}$ orgânico foi determinado pelo método de Nessler (Jackson, 1965), após digestão sulfúrica $\left(\mathrm{H}_{2} \mathrm{SO}_{4} \mathrm{e}_{2} \mathrm{O}_{2}\right)$, do tecido vegetal. A determinação do $\mathrm{Cl}$ foi feita por titulação com $\mathrm{AgNO}_{3}$ após a extração em banho-maria (Malavolta et al., 1997). No extrato da digestão nitro-perclórica $\left(\mathrm{HNO}_{3} \mathrm{e} \mathrm{HClO}_{4}\right)$, foram determinados: $\mathrm{P}$, colorimetricamente, pelo método do molibdato; $\mathrm{K}$, por espectrofotometria de emissão atômica; $\mathrm{Ca}, \mathrm{Mg}, \mathrm{Mn}, \mathrm{Fe}, \mathrm{Cu}$ e Zn, por espectrofotometria de absorção atômica; e S, por turbidimetria do sulfato (Malavolta et al., 1997). A metodologia utilizada na determinação do B foi a colorimétrica, pela azometina H, após incineração em mufla (Malavolta et al., 1997).

Os resultados foram apresentados em gramas do nutriente por quilogramas de massa seca da folha. Os teores de cada nutriente na folha inteira e na porção clorofilada foram obtidos pela média ponderada dos teores de cada nutriente encontrados nas respectivas partes das folhas.

A análise estatística dos dados obtidos foi realizada comparando as médias pelo teste de Tukey, ao nível de significância de $5 \%$ de probabilidade. As análises estatísticas foram realizadas, utilizando-se do programa SANEST (Sistema de Análise Estatística).

\section{RESULTADOS E DISCUSSÃO}

De um modo geral, analisando os resultados apresentados nos histogramas, pode considerar-se que a região não clorofilada da folha apresentou a maior concentração de nutrientes na matéria seca, com exceção para N, S, B, Mn e Fe, independentemente da aplicação de B.

$\mathrm{A}$ avaliação do teor de $\mathrm{N}$ foliar pela região não clorofilada da folha, nas condições deste trabalho, estaria subestimando a concentração foliar deste elemento, pois o teor encontrado nesta parte da folha ficou abaixo do teor encontrado para a folha inteira e na porção clorofilada e muito abaixo do teor apresentado pela porção apical da folha (Figura 1).

O S tendeu a acumular-se tanto na região apical como na aclorofilada da folha, mas, em ambas as partes, o teor apresentado esteve acima do teor da folha inteira e da porção clorofilada (Figura 1).

$\mathrm{O} \mathrm{K}$ (Figura 1) e o $\mathrm{Cu}$ (Figura 3) distribuíram-se de forma homogênea nas diferentes porções da folha considerada, com exceção para a região aclorofilada, onde o teor foi bem maior.

O B, nutriente de mobilidade baixa, embora Marschner (1995) o considere de mobilidade intermediária, acumulou-se na porção apical da folha, principalmente nas plantas que receberam a aplicação foliar. Este acúmulo independeu da aplicação foliar, o que foi comprovado em um experimento paralelo, onde o B foi fornecido à planta via solo e se observou o mesmo resultado (Figura 2).

Para o B, a amostragem da região não clorofilada da folha, como sugerem alguns autores, estaria subestimando o teor médio de $\mathrm{B}$ da folha, considerando as plantas que foram adubadas com B. Para as plantas que não foram adubadas com $\mathrm{B}$, a região aclorofilada da folha poderia ser utilizada para representar o teor médio de B na folha inteira (Figura 2).

Para o Mn, a análise foliar da região aclorofilada da folha pode ser utilizada como estimativa do teor da folha inteira, visto que os teores encontrados em ambas as partes não diferiram entre si, mas observa-se que este elemento se acumulou principalmente na região apical da folha (Figura 4).

Quanto ao teor de Mn, convém ressaltar que a concentração encontrada nas análises feitas está muito acima do valor considerado adequado para a planta, que seria de 50 a $200 \mathrm{mg} \mathrm{kg}^{-1}$ ( Souza, 1999).

O elemento Fe diferencia-se dos demais nutrientes, pois distribui-se de uma maneira mais uniforme ao longo da folha "D", com exceção para a porção mediana, que apresentou um teor de $\mathrm{Fe}$ estatisticamente menor em relação às demais partes da folha (Figura 4). Para este nutriente, poder-se-ia seguir a recomendação de Malavolta et al.(1997) e Manica (1999).

As concentrações de $\mathrm{K}, \mathrm{Mg}, \mathrm{Fe}$ e $\mathrm{Cu}$ na porção apical da folha foram similares aos teores observados na folha inteira. Já os teores observados na porção aclorofilada da folha foram diferentes destes, com exceção para o Fe.

A porção clorofilada da folha poderia ser utilizada para estimar o teor médio da folha inteira para todos os nutrientes analisados, mas o resultado da análise da porção aclorofilada da 
TABELA 1 - Teores adequados dos nutrientes para o abacaxizeiro, considerando as diferentes formas de amostragem

\begin{tabular}{|c|c|c|c|c|c|}
\hline Nutriente & $\begin{array}{l}\text { M a lavo lta et a } 1 . \\
(1997) \\
\text { F o lha Inte ira ou } \\
\text { porção } \\
\text { ac lo ro fila da }\end{array}$ & $\begin{array}{l}\text { Boaretto et al. } \\
(1999) \\
\text { Porção } \\
\text { c lo ro fila da }\end{array}$ & $\begin{array}{l}\text { Reuter e } \\
\text { Rob ins o n } \\
(1988) \\
\text { P orção } \\
\text { ac lo ro fila da }\end{array}$ & $\begin{array}{l}\text { M a la volta (1992) } \\
\text { F o lha Inte ira o u } \\
\text { porção } \\
\text { a c lo ro fila da }\end{array}$ & $\begin{array}{l}\text { Jones et al. } \\
(1991) \\
\text { P o rção } \\
\text { c lo ro fila d a }\end{array}$ \\
\hline \multicolumn{6}{|c|}{ M acronutrientes $\left(\mathrm{g} \mathrm{k} \mathrm{g}^{-1}\right)$} \\
\hline $\mathrm{N}$ & $20-22$ & $15-17$ & $15-25$ & $20-30$ & $15-17$ \\
\hline $\mathrm{P}$ & $2,1-2,3$ & $0,8-1,2$ & $1,4-3,5$ & $2-2,3$ & $<1$ \\
\hline $\mathrm{K}$ & $25-27$ & $22-30$ & $43-65$ & $23-27$ & $22-30$ \\
\hline $\mathrm{C} \mathrm{a}$ & $3-4$ & $8-12$ & $2,2-4,0$ & $2-4$ & $8-12$ \\
\hline $\mathrm{Mg}$ & $4-5$ & $3-4$ & $4,1-5,7$ & $2-5$ & $<3$ \\
\hline $\mathrm{S}$ & $2-3$ & --- & $0,7-?$ & $2-3$ & --- \\
\hline \multicolumn{6}{|c|}{ M icronutrientes $\left(\mathrm{mg} \mathrm{kg}^{-1}\right)$} \\
\hline $\mathrm{B}$ & $30-40$ & $20-40$ & --- & $30-40$ & $>30$ \\
\hline $\mathrm{Cu}$ & $9-12$ & $5-10$ & $10-50$ & $9-12$ & $<10$ \\
\hline $\mathrm{Fe}$ & $100-200$ & $100-200$ & $80-150$ & $100-200$ & $100-200$ \\
\hline $\mathrm{Mn}$ & $50-200$ & $50-200$ & $150-400$ & $50-200$ & $50-200$ \\
\hline $\mathrm{Zn}$ & $10-15$ & $5-15$ & $15-70$ & $10-15$ & $>20$ \\
\hline
\end{tabular}

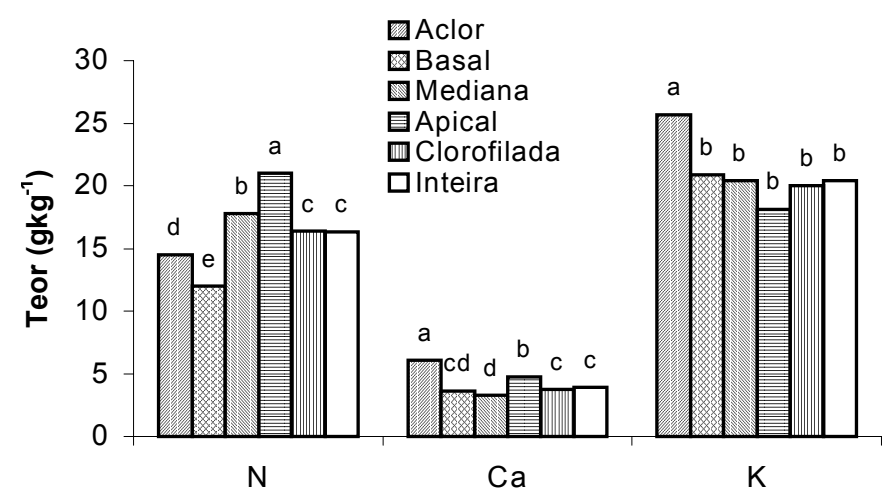

Nutrientes

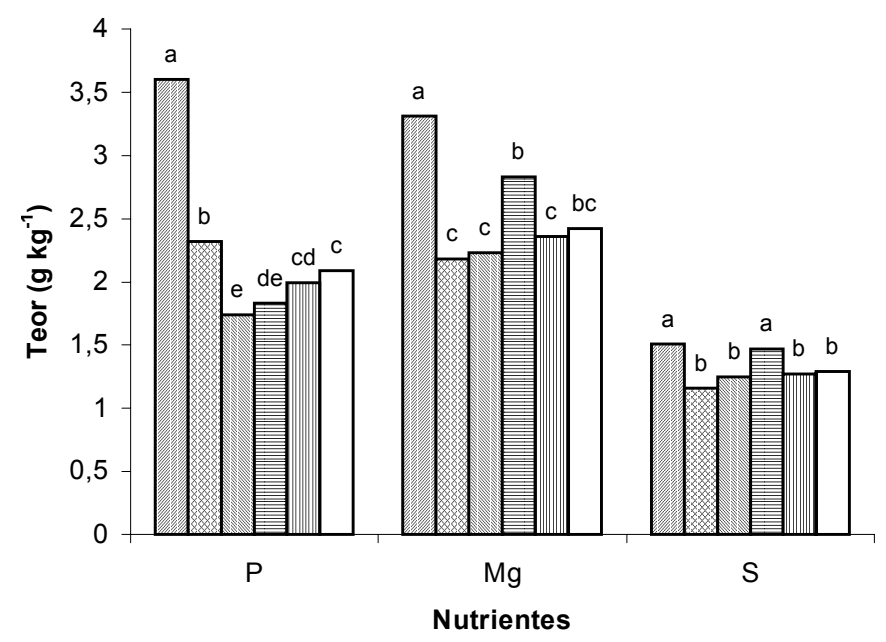

FIGURA 1 - Teor de macronutrientes em diferentes partes da folha do abacaxizeiro.

* Histogramas seguidos da mesma letra não diferem entre si , a $5 \%$, pelo teste Tukey.

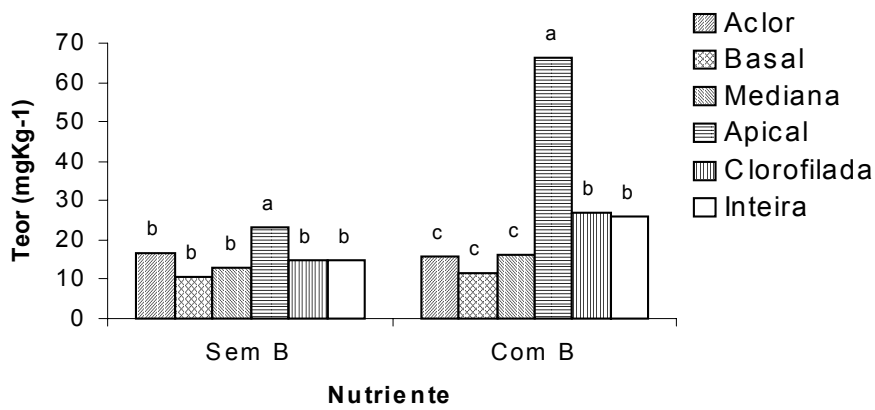

FIGURA 2 - Teores de B nas diferentes partes da folha de abacaxizeiros, sem e com pulverização de solução de bórax a $0,3 \%$.

* Histogramas seguidos da mesma letra não diferem entre si , a $5 \%$, pelo teste Tukey

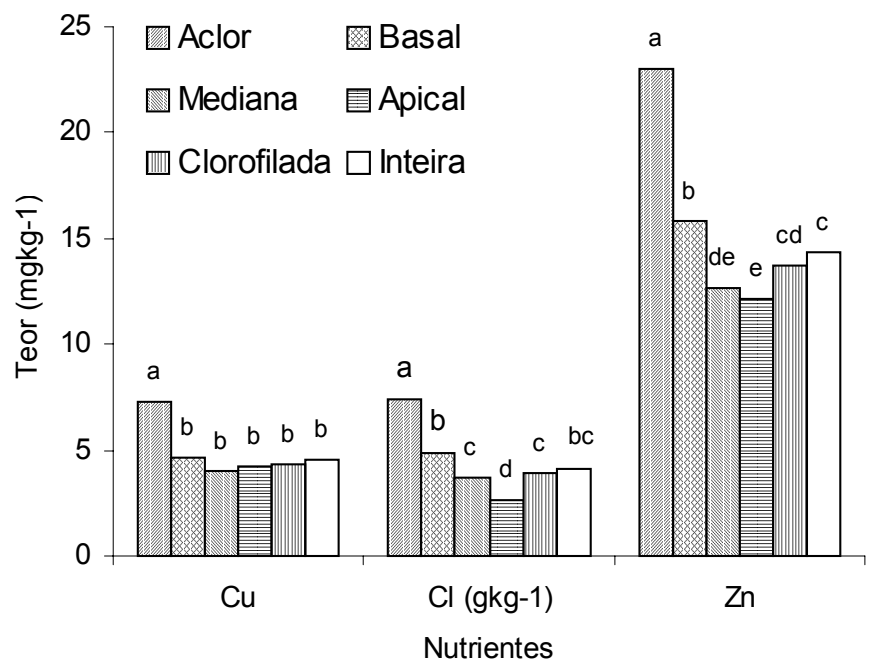

FIGURA 3 - Teores de Cu e Zn, em mg kg-1, e de Cl, em g kg-1 em diferentes partes da folha do abacaxizeiro.

* Histogramas seguidos da mesma letra não diferem entre si , a $5 \%$, pelo teste Tukey. 


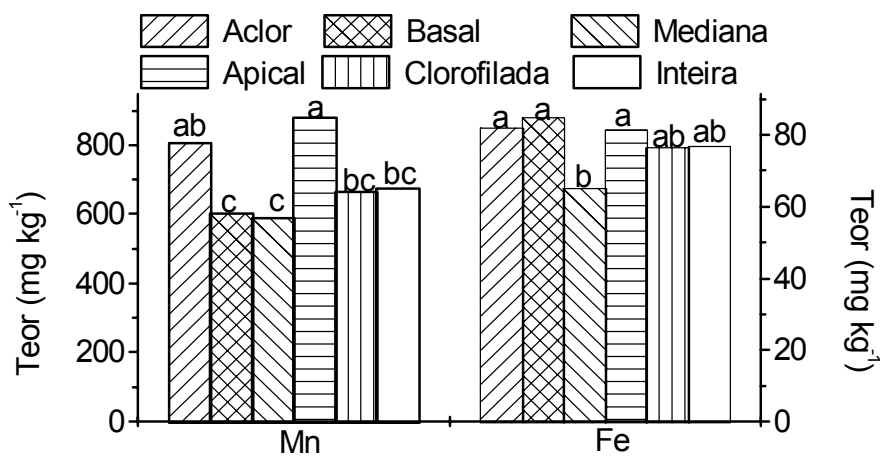

Nutrientes

FIGURA 4 - Teores de Mn e Fe em diferentes partes de folha do abacaxizeiro.

*Histogramas seguidos da mesma letra não diferem entre si , a $5 \%$, pelo teste Tukey.

folha não pode ser comparado com o da porção clorofilada da folha, com exceção para o Fe.

A grande variação da composição mineral observada ao longo da folha " $D$ ", neste experimento, também foi observada em outras plantas, tais como: milho (Jones, 1970, citado por Jones et al., 1991) e mamoeiro (Marinho, 1999).

Em milho, Jones (1970), citado por Jones et al. (1991), após encontrar os teores diferenciados de nutrientes ao longo da folha, afirma que o uso de partes da folha na análise foliar poderia gerar resultados com interpretação diferente da obtida com as folhas inteiras.

Os teores encontrados no limbo foliar do mamoeiro são diferentes dos encontrados no pecíolo, e mesmo ao longo do pecíolo foi observado um gradiente de concentração dos nutrientes analisados. Estes resultados levam a autora a afirmar que se deve ter o máximo de cuidado na coleta do material para a análise foliar, utilizando a porção mediana do pecíolo e eliminando-se proporcionalmente as porções apical e basal do pecíolo (Marinho, 1999).

Os resultados obtidos neste trabalho, comparados com os apresentados na Tabela 1, vêm confirmar que não é aceitável sugerir o uso de uma ou outra parte da folha na análise foliar, pois os valores obtidos nas diferentes partes da folha, por exemplo, na porção aclorofilada, se fossem comparados ou mesmo considerados como sendo da folha inteira, incorreriam em erros, que poderiam levar a recomendações de adubação erradas. Ao considerar a porção clorofilada da folha e a folha inteira, é possível estabelecer essa comparação.

Os trabalhos citados, juntamente com os resultados apresentados neste experimento, vêm confirmar a necessidade da padronização da amostragem.

Como afirma Jones et al. (1991), “o objetivo primário da análise foliar é utilizar a parte da planta cujos resultados da análise possam ser comparados com valores interpretativos conhecidos e aceitos"; para isto, é preciso padronizar a amostragem, não podendo utilizar diferentes partes da folha. Desta forma, inúmeros estudos ainda precisam ser desenvolvidos a fim de se estabelecer a padronização e uma possível comparação entre os resultados encontrados.

A padronização deve ser feita tanto para a parte da folha a ser analisada como para época de amostragem.
Estudos posteriores são necessários para a padronização da época de amostragem. A amostragem antes da indução floral, como sugerem Malavolta et al. (1997), é extremamente importante, pois antecede o período de maior demanda de nutrientes para a formação do fruto, mas é necessário estabelecer um padrão, pois, provavelmente, os teores dos nutrientes ao longo do ciclo de desenvolvimento da planta também variam.

\section{CONCLUSÃO}

1. Os teores de $\mathrm{P}, \mathrm{Mg}, \mathrm{K}, \mathrm{Ca}, \mathrm{Cu}, \mathrm{Cl}, \mathrm{Zn}$ e foram maiores na porção aclorofilada da folha. $\mathrm{O} \mathrm{Fe}$, $\mathrm{S}$ e o Mn distribuíram-se ao longo da folha. $\mathrm{O} \mathrm{N}$ e o B concentraram-se principalmente na porção apical da folha.

2. A variação dos teores dos nutrientes ao longo da folha " $D$ " do abacaxizeiro não permite que sejam comparadas análises feitas com diferentes partes da folha.

3. Uma comparação confiável pode ser estabelecida entre análises feitas com a folha " $D$ " inteira e a sua porção clorofilada.

4. Este trabalho vem confirmar a necessidade de padronização da amostragem foliar, quanto à parte de folha a ser analisada.

\section{REFERÊNCIAS BIBLIOGRÁFICAS}

BOARETTO, A.E.; CHITOLINA, J.C.; RAIJ, B. van; SILVA, F.C.; TEDESCO, M.J.; CARMO, C.A.F.S. Amostragem, acondicionamento e preparação das amostras de plantas para análise química. In: Manual de análises químicas de solos plantas e fertilizantes. EMBRAPA DE SOLOS, EMBRAPA INFORMÁTICA E AGROPECUÁRIA, Brasília: EMBRAPA COMUNICAÇÃO PARA A TRANSFERÊNCIA DE TECNOLOGIA, 1999. p. 49-73.

JACKSON, M.L. Soil chemical analysis. New Jersey: Prentice Hall, $1965.498 \mathrm{p}$.

JONES Jr. J.B.; WOLF, B.; MILLS, H.A. Plant Analysis Handbook: a pratical sampling, preparation, analysis, and interpretation guide. Athens (USA): Micro-Macro Publishing. 1991, 213 p.

MALAVOLTA, E. ABC da análise de solos e folhas: amostragem, interpretação e sugestões de adubação. São Paulo: Agrônomica Ceres, $1992.124 \mathrm{p}$.

MALAVOLTA, E. Nutrição mineral e adubação do abacaxizeiro. In: SIMPÓSIO BRASILEIRO DE ABACAXICULTURA, 1. 1982, Jaboticabal. Anais... p. 121-153.

MALAVOLTA, E.; VITTI, G.C.; OLIVEIRA, S.A. Avaliação do estado nutricional das plantas: princípios e aplicações. 2 . ed. Piracicaba: POTAFOS, 1997.319 p.

MANICA, I. Fruticultura Tropical 5. Abacaxi. Porto Alegre: Cinco Continentes, 1999. $501 \mathrm{p}$.

MARINHO, C.S. Avaliação do estado nutricional e adubação do 
mamoeiro (Carica papaya L.) no Norte Fluminense. Campos dos Goytacazes, 1999. 80 p. Dissertação (Doutorado em Produção Vegetal) Universidade Estadual do Norte Fluminense - UENF.

MARSCHNER, H. Mineral Nutrition of Higher Plants. 2 ed. London: Academic Press, 1995. 675p.
REUTER, D.J.; ROBINSON, J.B. Plant analysis - na interpretation manual. Melbourne: Inkata Press, 1988.218 p.

SOUZA, L.F.S. Exigências edáficas e nutricionais. In: $\mathbf{O}$ abacaxizeiro: cultivo, agroindústria e economia. Brasília: EMBRAPA COMUNICAÇÃO PARA A TRANSFERÊNCIA DE TECNOLOGIA, 1999.p. 67-77. 